\title{
Memorabeatlia: A naturalistic study of long-term memory
}

\author{
IRA E. HYMAN, JR. \\ Emory University, Atlanta, Georgia \\ and \\ DAVID C. RUBIN \\ Duke University, Durham, North Carolina
}

\begin{abstract}
Seventy-six undergraduates were given the titles and first lines of Beatles' songs and asked to recall the songs. Seven hundred and four different undergraduates were cued with one line from each of 25 Beatles' songs and asked to recall the title. The probability of recalling a line was best predicted by the number of times a line was repeated in the song and how early the line first appeared in the song. The probability of cuing to the title was best predicted by whether the line shared words with the title. Although the subjects recalled only $21 \%$ of the lines, there were very few errors in recall, and the errors rarely violated the rhythmic, poetic, or thematic constraints of the songs. Acting together, these constraints can account for the near verbatim recall observed. Fourteen subjects, who transcribed one song, made fewer and different errors than the subjects who had recalled the song, indicating that the errors in recall were not primarily the result of errors in encoding.
\end{abstract}

Song lyrics are remembered very well, and almost daily, by many people. Some examples include people singing along with songs on the radio, songs being used to teach rote memorization (e.g., the ABC song), and oral traditions passing through generations (Kelly \& Rubin, 1988; Wallace \& Rubin, 1988a, 1988b). When compared with memory for other verbal material, memory for lyrics seems to be much more exact. How much easier is it to recall the words to a song one knew years before than to remember a geometry theorem one used daily in high school or even a lecture one gave just last week? One can get the gist of the geometry rule perhaps, or recall the topic and even a few of the examples of last week's lecture, but one rarely retrieves the exact words. The quick

We wish to thank Erin Cooperrider and David Tarbert for their help on the initial experiments that led to this study, David Tarbert for his help in conducting the recall experiment, Kevin Mallory for his technical assistance with the data analysis, Gene Winograd and Angela Harwood for their comments on earlier drafts, Ira Hyman's Spring 1989 Experimental Methods students for participating as the subjects in the perception experiment, and Wanda Wallace for help with the data analysis and support throughout the research project. Support was provided by NSF Grant BNS-8410124. Portions of this paper were presented at the Annual Conference of the American Psychological Association, August 1988, Atlanta, Georgia. Correspondence should be addressed to Ira E. Hyman, Department of Psychology, Emory University, Atlanta, GA 30322 .

“'Rocky Raccoon' by John Lennon and Paul McCartney (C) 1968, 1969 NORTHERN SONGS LTD. All rights for the U.S., Canada, and Mexico controlled and administered by EMI BLACKWOOD MUSIC INC. under license from ATV MUSIC (MACLEN). All Rights Reserved. International Copyright Secured. Used by Permission. answer that the songs have been repeated more often than the lecture does not adequately explain the phenomenon. An investigation of memory for song lyrics can illuminate factors that allow for such excellent recall.

To investigate memory for song lyrics, we asked subjects to recall Beatles' songs when given the title and the first line, and we asked different subjects to remember the title when cued with one line from a song. Although songs by the Beatles are not the kind of material usually studied by cognitive psychologists, they have several characteristics that make them well suited for such research, including the following: (1) clearly defined units (the lines), which can be scored for recall; (2) a complex, but analyzable, structure that depends on meaning, imagery, poetics, rhythm, and emotional connotations; (3) a large, well-defined corpus from which to select; (4) material that is already learned and interesting to many potential subjects; and (5) lyrics that were better known at an earlier time, which is a property that facilitates cuing studies.

Researchers have discovered various objective properties of stimuli, such as repetition, serial position, and imagery, that are related to memory for verbal materials. We relied on these findings to guide our investigation of factors related to the mnemonic qualities of lines: how often lines were recalled when given the title and first line, and the probability of lines' functioning effectively as cues to the title. Often theorists have treated free recall and cued recall as endpoints on a continuum of memory functions (Tulving \& Watkins, 1973; Watkins, 1979). Although the goal in both recalling songs and cuing titles is to reach other lines from the information given, the task may be addressed differently in recall and cuing. Our in- 
vestigation of the factors related to recall and cuing will provide insight into the memory strategies used.

In addition to examining the proportion recalled and proportion cued measures, in this research, we investigate and describe memory for song lyrics on the basis of the descriptive techniques of Bartlett (1932). Bartlett looked at the errors in recall for clues to how memory functions. He assumed that the mistakes would be guided by the same processes that directed accurate recall and would thus fall into patterns that would identify the underlying processes. In remembering the "War of the Ghosts" story, his subjects reconstructed the story on the basis of their understanding of it.

We will report our examination of the errors made in recalling song lyrics as a means of illustrating the factors that direct and constrain memory. When recalling the Beatles' songs, our subjects could have been engaged in a reconstructive task similar to someone recalling a story. A person recalling a story is constrained in selecting words primarily by the meaning, which leaves great room for variance in word choice. The recall of a song, however, is constrained by the poetics and rhythm as well as the meaning, which greatly reduces the number of words that can be used at any point. It has often been shown that meaning directs recall and that the general theme is what is most often recalled by subjects (Bartlett, 1932; Horton \& Mills, 1984; Kintsch, 1974; Kintsch, Kozminsky, Streby, McKoon, \& Keenan, 1975; Neisser, 1982; Rubin, 1978). In our research, the addition of more constraints could enhance the accuracy of reconstructive recall.

A combination of these two methods of analysis will paint a more complete picture of memory that illustrates the mnemonic ties between lines that determine what will be recalled and the constraints on reconstruction that determine the exact words used in recall. After outlining the methods used to obtain all measures-the dependent measures of recall and cue strength; the independent measures of meaning, imagery, emotionality, and poetics; and the measure of the ability of subjects to transcribe a song accurately-the results of several analyses will be presented. The first set of analyses addresses the factors related to the questions of which lines were recalled well and which lines functioned effectively as cues to the title. The second set addresses the reconstructive nature of recall by examining the errors.

\section{METHOD}

Because we were concerned with the properties that are related to the mnemonic value of songs, the line was the unit of analysis. For each line, various measures were gathered. Each subject participated in only one part of the data collection.

\section{Recall}

The measure of how often each line was recalled was taken from an experiment in which subjects were asked to write entire songs when given the titles and first lines. Sixty-four of the over 200 Beatles' songs were chosen randomly from a published corpus (Savile, 1979) and divided into two groups. Each subject received a booklet containing 32 lined pages, each of which began with the title and first line of a different song (randomized for each booklet).
The booklets contained instructions to write as much of each song as possible. Seventy-six introductory psychology students (during the 1982-1983 academic year) received between .5 and $2.5 \mathrm{~h}$ of credit toward a subject participation requirement equivalent to the time they spent recalling the songs. The subjects generally enjoyed this task and worked hard to recall as much as they could. Each line in every song could have been recalled by 38 subjects. Because many of the randomly selected songs were obscure, the level of recall was lower than optimal for statistical prediction. Therefore, the 25 songs with the highest level of recall were chosen for further research. The songs used were: "A Day in the Life," "All You Need is Love," "Can't Buy Me Love," "Come Together," "Day Tripper," "Drive My Car," "Eleanor Rigby," "Getting Better," "Got to Get You into My Life," "Help," "Helter Skelter," "Hey Jude," "Lady Madonna," "Michelle," "'Nowhere Man," “'Obladi Oblada," "Penny Lane," " Revolution," "'Rocky Raccoon," "She Loves You," "Strawberry Fields Forever," "The Fool on the Hill," "When I Saw Her Standing There," "Yellow Submarine," and "Yesterday."

\section{Cuing}

The measure of cue strength was obtained from an experiment in which subjects were given one line as a cue and asked to write the title, first line, and one other line from the song. The subjects were given booklets containing a page of instructions and 25 pages with one line from each song. For each booklet, the order of the 25 songs was randomized. The subjects were informed only that the lines were taken from Beatles' songs. Booklets were given to 704 introductory psychology students as part of the subject participation requirement in the 1983-1984 and 1984-1985 academic years.

Because each booklet contained only 1 line from each song, the number of subjects receiving each line varied with the length of the song. Beatles' songs contain some lines that repeat. Lines that repeated verbatim apart from changes in function words as opposed to content words (Fries, 1952) were considered repetitions. In the cuing experiment, in the poetic analyses, and in all statistical analyses, repeating lines were included as if they had occurred only once. As a result, the songs varied in length from 8 to 30 lines. The song containing 8 lines was included in only half of the booklets, because that provided ample opportunities for each line to serve as a cue. On the average, 35 subjects were cued by each line. The cue strength measure was the proportion of successful cues to the title divided by total cue opportunities.

\section{Simple Objective Properties of the Songs}

The lines of the Beatles' songs have several properties that could affect memory. These include the following: repetition, which refers to the number of times a line repeats in the song; primacy, which refers to when the line first enters the song, multiplied by minus one so that in correlational analyses positive correlations imply a positive effect; line in verse, which denotes the line number within the verse on which the line first enters; words per line, which denotes the number of words in the line; and shared content words, which refers to whether or not the line shares content, as opposed to function words, with the title (scored 0 if there were no shared content words, 1 if there were some shared content words, and 2 if all the title's content words were contained in the line).

We expected that each of these variables could have been related to recall and cuing. Repetition has been shown to affect memory in studies too numerous to cite. Serial position, operationalized as primacy and line in verse, has been a variable of interest for years in memory for word lists and has an especially important role in some poetic material (Rubin, 1977). Words per line could be postulated to affect recall and cuing in a number of ways, and so this variable needed to be examined, even though no single strong prediction was made. Shared content words was expected to increase both recall and cuing. 
In this research, we have not examined music. In terms of trying to understand which lines are well recalled, we found it difficult to find a quantifiable measure that could differentiate the music associated with one line from the music associated with another and thus be part of an explanation of why one line is recalled and another not. The music may be a better cue to give for recall of the whole song, but in this research we were not interested in comparing musical and verbal cues. For these reasons, our only attempts to take into account the musical qualities of the songs consisted of the poetic measures discussed next and the measure of rhythm used in the error analyses.

\section{Poetics}

Several measures of poetics were formulated, because the poetic value of each line can be based on its relation to its song, to its verse, or within itself, and for each of these, the sound noted could be rhyme, alliteration, or assonance. The poetic values used in this study included the number of end rhymes across the song, the number of alliterations across the song, a measure of poetics within each line, and a measure of each line's poetic ties to its verse.

End rhyme is a common poetic device, one that the Beatles frequently used. For each line, the measure of end rhyme was equal to the number of other lines in the song with which it rhymed, plus the number of other lines with which it shared the same last word. Alliteration, a symmetrical measure, consisted of the number of lines with which the line alliterated plus the number that had the same first word. These poetic devices were common, with $76 \%$ of the lines rhyming and $74 \%$ of the lines alliterating. End rhyme varied from 0 to 7 and alliteration varied from 0 to 20 .

For the measure of within-line poetics, each line was assigned a value equal to the sum of the number of repeated words, thymes, alliterations, and assonances that it contained. Parts of words could be counted in sets of sounds that contained rhyme, alliteration, or assonance; but a sound pattern, be it a word or a part of a word, could only be counted once. A similar measure was calculated for each line within its verse. Even though the Beatles' songs sampled contained a great deal of within-line and within-verse poetics, neither was related to either the recall or cuing variables; therefore, they are not considered further in the analyses of factors related to the mnemonic quality of lines.

\section{Rated Measures}

In order to capture and use factors that might influence memory but that could not be counted, each line was rated on imagery, theme, and emotion. Booklets contained instructions and 25 rating pages with one song typed on each. The order of the 25 songs was randomized.

For the imagery rating, subjects were asked to write down the overall image created by the song and then to rate each line on a 7-point scale, measuring the ease with which the line aroused an image (adapted from Paivio, Yuille, \& Madigan, 1968). The description of the overall image was required to ensure that the subjects thought about each song as a whole before performing the ratings. The subjects were given this task because the goal of the first set of analyses was to find out what it was about lines that added to their mnemonic relations to song (Rubin, 1978). Thus, the ratings were of each line's image arousing ability, with the subjects first oriented to the entire song.

The same procedure was followed for the other two scales. The subjects rated each line on its importance to the theme and the ease with which it aroused an emotion. For each scale, 27 different introductory psychology students rated all songs during the 1983-1984 academic year. The measures for each line are the means from these ratings.

\section{Perception}

From the recall data alone, it is impossible to determine if ob served distortions were due to initial encoding difficulties or to memory processes. Therefore, during the 1988-1989 academic year,
14 subjects listened to "Rocky Raccoon" one line at a time and wrote down what they perceived to be the words. The subjects were Emory University Psychology majors, who voluntarily participated as part of a class demonstration. The song "Rocky Raccoon" was selected, because it was the median song in terms of the average number of subjects who recalled each line in the recall data. Because the data were collected approximately 5 years after the recall and cuing data, these subjects were much less familiar with the song; 9 of 14 subjects claimed never to have heard the song before, and only 1 of the subjects claimed to know more than just a few lines. Thus, for these subjects, long-term memory of the song played at most a small role.

The song was played one line at a time, with $15-\mathrm{sec}$ pauses between the lines, during which the subjects wrote the lines down. The song was played three times. The subjects were told to write down the exact words of the song as accurately as they could, relying only on the recording being played and not on any previous knowledge of the song. After the subjects had finished, the song was played in its entirety. In order to simulate what would be the worst possible listening conditions of the subjects in the recall and cuing studies, the tape was a twice removed recording of a wellworn album, and it was played on a 2-year-old portable cassette stereo. Five days later, the subjects were given a memory test. They were given the title and first line and asked to write down as much of the song as they could.

\section{RESULTS}

The first set of analyses was used to investigate the factors related to the mnemonic value of the lines. The two dependent measures were recall, the proportion of times each line was recalled when given the title and the first line, and cuing, the proportion of successful cues to the title by each line. Although both measures can be viewed as forms of cued recall (either by the title and the first line or the line in question), we use recall and cuing as easy-to-follow definitions of our procedures and to specify on which end of the continuum from free recall to recognition the data fell (Tulving \& Watkins, 1973; Watkins, 1979). In the recall measure, as in most measures in the literature, the question is whether the line was recalled as part of a large list. In the cuing measure, as in most cuing measures in the literature, the question is whether the line successfully cued a single item, in this case the title. The independent or predictor measures were the objective, poetic, and rated measures of the lines.

For the second set of analyses, the errors made in recalling the lines were scrutinized to reveal the factors that constrained recall. We determined whether the errors conformed to the thematic, rhythmic, and poetic constraints. We also reviewed the errors made during the perception experiment, to ascertain if the recall errors were due to encoding or retrieval.

The scoring of the two dependent measures is presented first, followed by the reliabilities of both the dependent measures and the three rated measures.

\section{Scoring}

When a set of words did not match any line in the song completely, the decision as to which line was recalled was based on which line the recalled content words most closely resembled, and on where in the order of recall 
Table 1

Means and Standard Deviations of Included Variables

\begin{tabular}{llrr}
\hline \multicolumn{1}{c}{ Variable } & \multicolumn{1}{c}{ Name } & \multicolumn{1}{c}{$\boldsymbol{M}$} & \multicolumn{1}{c}{$S D$} \\
\hline Mean emotion rating & Emotion & 4.15 & .87 \\
Mean imagery rating & Imagery & 4.26 & .95 \\
Mean thematic rating & Theme & 5.01 & .89 \\
Number of repetitions & Repetitions & 1.49 & 1.15 \\
Order of entry & Primacy & 12.32 & 7.53 \\
Line in verse & Verse line & 2.83 & 1.54 \\
Words per line & Words & 7.02 & 2.36 \\
If line shares words with the title & Shared & .37 & .71 \\
Number of end rhymes & Rhyme & 1.75 & 1.73 \\
Number of first-word alliterations & Alliteration & 2.52 & 2.44 \\
Proportion of times recalled & Recall & .21 & .17 \\
Proportion of successful cues to the title & Cuing & .25 & .22 \\
\hline
\end{tabular}

the subject had positioned the set of words. In practice, this task was usually trivial; few words were altered, and the subjects usually wrote the songs in the correct order. Furthermore, there was only a handful of cases in which a set of words could not be recognized as belonging to the song at all. For repeated lines, any recall of the line in any of its positions was counted as recall of the line, and the line was counted only once, regardless of how many times the subject wrote it.

In the cuing experiment, the same criteria were applied. A subject was given credit for remembering the title if the words written distinguished it from other titles. As in the recall data, few words were altered. There were 17,248 opportunities for responses and 5,339 responses, of which 4,356 (82\%) were correct. Because there were some errors, it is likely that some guessing occurred. However, the low percentage of errors and the low a priori probability of guessing a title from a line without any prior exposure to the title indicate that guessing played a minor role in the results.

\section{Reliabilities}

Recall. Two judges independently scored 10 subjects' recalls of every song. The correlation between their two scorings calculated over the 457 lines of the 25 songs was .95. Cronbach's alpha was used to estimate how well the recall values obtained here would correlate with those from the same number of new subjects drawn from the same population. Recall values were obtained from 38 subjects for one set of 11 songs and from 38 different subjects for the remaining 14 songs. Cronbach's alpha for these sets was .92 and .93 .

Cuing. Two judges independently scored booklets from 50 subjects. The interjudge correlation was .97 . A reliability for the cuing dependent measure is difficult to determine using a standard formula, because each subject only saw one line per song. Approximately half the subjects took part in the experiment in each of two semesters. The correlation between the two semesters' scores, corrected with the Spearman-Brown prophecy formula, is .89. This value is a conservative split-half measure of reliability.

Rating scales. Cronbach's alpha for the imagery, theme, and emotionality ratings was $.90, .90$, and .91 , respectively.

\section{Unit Analysis}

For all the following analyses, the first lines of songs were excluded due to their use as cues in the recall data collection. Without these, there were 432 lines in the 25 Beatles' songs studied. Table 1 presents the means and standard deviations of the variables. Table 2 shows the correlations among the variables. Two additional variables are included in Table 2: corrected recall and corrected

Table 2

Correlation Matrix

\begin{tabular}{lrrrrrrrrrrrrr}
\hline \multicolumn{1}{c}{ Variables } & 1 & 2 & 3 & 4 & 5 & 6 & 7 & 8 & 9 & 10 & 11 & 12 & 13 \\
\hline 1. Emotion & & & & & & & & & & & & \\
2. Imagery & 23 & & & & & & & & & & & \\
3. Theme & 75 & 20 & & & & & & & & & & \\
4. Repetition & 06 & -10 & 16 & & & & & & & & & \\
5. Primacy & 07 & 06 & 09 & 20 & & & & & & & & \\
6. Verse line & 01 & 11 & 08 & 09 & 25 & & & & & & & \\
7. Words & 22 & 29 & 15 & -09 & 07 & 04 & & & & & & \\
8. Shared & 08 & 02 & 20 & 34 & 02 & 11 & -11 & & & & & \\
9. Rhyme & 04 & -04 & 05 & 01 & 00 & -04 & -03 & 05 & & & & \\
10. Alliteration & -22 & -12 & -20 & -14 & -11 & -07 & -09 & 01 & 11 & & & \\
11. Recall & 14 & 05 & 13 & 52 & 43 & 09 & -03 & 32 & 11 & -16 & & \\
12. Corrected Recall & 02 & 02 & 08 & 56 & 41 & 07 & -04 & 29 & 07 & -13 & 88 & \\
13. Cuing & 05 & 09 & 12 & 27 & 14 & 07 & -10 & 66 & 17 & 07 & 48 & 40 & \\
14. Corrected Cuing & -03 & 06 & 09 & 33 & 09 & 04 & -10 & 67 & 06 & 05 & 37 & 44 & 85 \\
\hline
\end{tabular}

Note-Leading decimals omitted. 
cuing. These are the recall and cuing scores for each line, with the mean recall or cuing level of the song subtracted. They were included in an attempt to remove the effects of the differential popularity of the songs. Of course, if two songs were equally popular, but one was more memorable, the adjustment would remove an effect that should not be removed. Thus, the two corrected measures are included in addition to, rather than instead of, the unadjusted values.

Recall and cuing were correlated with one another $(r=.48)$, indicating an underlying memory factor but also showing a difference in the two measures. The independent variables most strongly correlated with recall were the number of repetitions $(r=.52)$, primacy $(r=$ .43 ), and whether the line shared words with the title ( $r$ $=.32$ ). For cuing, whether the line shared words with the title dominated the correlations $(r=.66)$. The number of repetitions and the number of end rhymes were correlated at weaker levels $(r=.27$ and $r=.17$, respectively). When the correlations were computed only with the lines that did not share words with the title $(n=328)$, the imagery rating was also correlated with cuing $(r=$ .18), but no other independent variable was correlated with an $r$ greater than .10 .

Table 3 presents stepwise multiple regression analyses, conducted such that all independent variables were allowed to enter the equations as long as the $F$ to enter was greater than 4.0. These regressions are presented for both the recall and cuing measures as well as for the two corrected measures.

Indicated in the correlations and the regressions are several consistent findings. For both measures of recall, the number of times a line repeats in a song, the primacy of the line in a song, and whether the line shared words with the title were the major predictors. For both measures of cuing, the major predictor was whether or not the line shares words with the title. The effect was so large that it obscured most other variables, with only imagery appearing in both regressions.

In summary, recall and cuing appeared to be different, albeit related, variables. Although both had reliability coefficients of about .9 , they correlated with each other only at $r=.48$. In addition, different sets of variables were related to recall and cuing. Repetition and primacy consistently affected only recall. This was due to the fact that subjects began recalling the songs with the first line and continued as far as they could with the chorus often being reached. This correlational finding is consistent not only with the order of recall in the protocols, but also with earlier work on the serial learning of lists (Kausler, 1974) and with the recall of other verse from long-term memory (Rubin, 1977). In contrast, both whether or not a line shared words with the title and the rated imagery had larger effects in cuing than in recall. Lines that contain part of the title should be good cues for the title, but one would also expect them to be cued more frequently by the title and first line and therefore to be recalled well. The difference in the size of the effects appears to be due to the strategies of retrieval that the subjects used in the two conditions. For recall, the effects of the title and first lines as cues were lessened by interitem cuing, since the subjects recalled the songs in order, whereas for cuing, the information available in the cue was more important, because the subjects were trying to go straight from that line to the title. The importance of imagery in cuing is a standard effect in verbal learning studies (Paivio, 1965; Rubin, 1980), and it is supported by more naturalistic cuing studies (Neisser \& Hupcey, 1974).

\section{Analysis of Errors in Recall}

Across all subjects and songs in the recall data collection, there were 3,378 lines remembered out of 16,416 opportunities for lines to be recalled (each of the 432 lines could have been recalled by 38 subjects). Our subjects failed to recall nearly four-fifths of the lines. In spite of this, most of the remembered lines were recalled verbatim. Of the 3,378 lines remembered, $70 \%(2,371)$ were recalled perfectly, while $20 \%$ (681) were recalled with changes of one or two words and only $10 \%$ (326) were recalled with changes of three or more words. Errors of commission were infrequent and generally small. If one assumes that the same processes are functioning during both exact recall and somewhat erroneous recall, then, through an examination of the errors, the reconstructive nature of recall should become evident. Most of the errors adhered to the meaning of the lines, maintained the rhythmic structure of the songs, and either did not alter words involved in the poetic structure or upheld the poetic constraints. In this section, we investigate the factors that constrained the recalls.

Conservation of meaning. When recalling the lines, subjects attempted to maintain the thematic information

Table 3

Stepwise Multiple Regressions

\begin{tabular}{|c|c|c|c|c|c|c|c|}
\hline \multirow[b]{2}{*}{ Dependent Variable } & \multicolumn{7}{|c|}{ Independent Variables and Order of Steps } \\
\hline & Intercept & 1 & 2 & 3 & 4 & 5 & Multiple $r$ \\
\hline Recall & .19 & $\begin{array}{c}+.06 \\
\text { Repetition }\end{array}$ & $\begin{array}{c}+.01 \\
\text { Primacy }\end{array}$ & $\begin{array}{c}+.05 \\
\text { Shared }\end{array}$ & $\begin{array}{c}+.01 \\
\text { Rhyme }\end{array}$ & $\begin{array}{c}-.01 \\
\text { Alliteration }\end{array}$ & .65 \\
\hline Corrected Recall & -.03 & $\begin{array}{c}+.06 \\
\text { Repetition }\end{array}$ & $\begin{array}{c}+.01 \\
\text { Primacy }\end{array}$ & $\begin{array}{c}+.03 \\
\text { Shared }\end{array}$ & $\begin{array}{c}-.01 \\
\text { Verse line }\end{array}$ & & .66 \\
\hline Cuing & .08 & $\begin{array}{c}+.21 \\
\text { Shared }\end{array}$ & $\begin{array}{c}+.01 \\
\text { Rhyme }\end{array}$ & $\begin{array}{c}+.01 \\
\text { Primacy }\end{array}$ & $\begin{array}{c}+.02 \\
\text { Imagery }\end{array}$ & & .69 \\
\hline Corrected Cuing & -.09 & $\begin{array}{c}+.17 \\
\text { Shared }\end{array}$ & $\begin{array}{c}+.02 \\
\text { Repetition }\end{array}$ & $\begin{array}{c}-.02 \\
\text { Emotion }\end{array}$ & $\begin{array}{c}+.02 \\
\text { Imagery }\end{array}$ & & .69 \\
\hline
\end{tabular}


contained in the lines. It is very difficult to quantify whether the changes affected the meaning of the line, and thus we, like Bartlett (1932), resort to examples as the most convincing proof. The song "Rocky Raccoon" and all of the errors subjects made are shown in Table 4. This song was chosen because it was the median song in the number of recalls per line. The correct wording of each line is given first and then any errors are presented in italics. It is difficult to read through these and find any examples where the basic meaning was changed. Errors such as substituting "went" for "walked" in line 6, "'head" for "legs" in line 11, "shoot out the lights" for "shoot off the legs" in line 11, and "collapsed on the table" for "collapsed in the corner" in line 21 preserved the general theme, even if they did change the words. A few changes altered the meaning of the lines-"checked grinning a grin" for "checked into his room" in line 8 and "Rocky" for "Danny" in line 19-but these are the only obvious ones.

Overall, there were some mistakes in meaning, but they were few and far between in the recalls. This should not come as any surprise to the reader, due to the overwhelming evidence that in recall the meaning or gist of the material is maintained (Bartlett, 1932; Horton \& Mills, 1984; Kintsch, 1974; Kintsch et al., 1975; Neisser, 1982).

Conservation of rhythm. In order to judge if the subjects were conforming to the rhythmic structure, a count of syllables was used. An error was considered to hold the rhythmic structure constant if the number of syllables in the substitution was equal to the number replaced. By this means, it was known whether the change could have been sung with the same meter as the original. It is possible in singing the songs for two syllables to be squeezed into the space allocated to one, or for one syllable to be stretched to fill the space originally occupied by more than one, but this changes the match between the words and the beat.

The number of syllables was altered in only 329 of the 1,007 erroneous recalls: thus $67 \%$ of the changes conformed to the rhythmic structure. The song "Rocky Raccoon" also shows the accuracy of errors in maintaining the meter of the lines (see Table 4). In only 9 of the 44 changes did the subjects alter the number of syllables. Errors such as "stepped," "walked," or "went" for "checked" in line 8, "up to" for "into" in line 8, "most people" for "everyone" in line 15 , and "went down by the table" for "collapsed in the corner" in line 21 all maintained the number of syllables.

Conservation of poetics. As has already been noted, there are several poetic relations between the words of the Beatles' songs. When recalling the songs, the subjects seldom violated any of these poetic constraints. The most striking case is that of end rhymes. In only 170 of the 1,007 lines recalled with errors was the last word of a line changed. Because on the average there are 2.28 words changed in each erroneous recall and 7.02 words in each line, one would expect that, if the errors were randomly distributed across word position in the lines, in 327 of
Table 4

Recall Errors in "Rocky Raccoon"

1. Now somewhere in the black mountain hills of Dakota [not scored, as the first line and title were used as the cue]

2. There lived a young boy named Rocky Raccoon (5) there lived a man named Rocky Raccoon (5) there was a man by the name of Rocky Raccoon there's a little raccoon named Rocky Raccoon there lives a critter called Rocky Raccoon

3. And one day his woman ran off with another guy (6)

4. hit young Rocky in the eye Rocky didn't like that (6)

5. He said I'm going to get that boy (5)

6. So one day he walked into town (4) so one day he went into town

7. Booked himself a room in the local saloon (4) bought himself $a$ room in the local saloon

8. Rocky Raccoon checked into his room (4) Rocky Raccoon stepped into his room (3)

Rocky Raccoon walked into his room (2)

Rocky Raccoon went into his room

Rocky Raccoon went up to his room

Rocky Raccoon checked grinning a grin

9. only to find Gideon's Bible (12) still holding on to Gideon's Bible started to read Gideon's Bible

10. Rocky had come equipped with a gun (5) Rocky set out equipped with a gun Rocky had come packing a gun

11. to shoot off the legs of his rival (3) to do in the legs of his rival to shoot off the head of his rival to shoot off the hands of his rival to shoot out the lights of his rival

12. his rival it seems had broken his dreams (7)

13. by stealing the girl of his fancy (7)

14. her name was Magill and she called herself Lill (7)

15. but everyone knew her as Nancy (7) but most people knew her as Nancy

16. Now she and her man who called himself Dan (4) now she and her man who called himself Stan

17. Were in the next room at the hoe down (15)

18. Rocky burst in and grinning a grin (3) Rocky walked in and grinning a grin Rocky went in and grinning a grin Rocky burst in and said with a grin

19. he said Danny boy this is a showdown (5) he said Rocky boy this is a showdown he said listen boy this is a showdown he said Danny boy here's a showdown

20. But Daniel was hot-he drew first and shot (6) but Rocky was hot-he drew first and shot but Daniel was hot-he took the first shot

21. and Rocky collapsed in the corner (6) and Rocky collapsed on the table and Rocky went down by the table

22. Now the doctor came in stinking of gin (7)

23. and proceeded to lie on the table (6) and sat down by the table

24. he said Rocky you met your match (10)

25. And Rocky said, Doc it's only a scratch (10)

26. And I'll be better, I'll be better Doc as soon as I am able (10)

27. Now Rocky Raccoon he fell back in his room (5) now Rocky Raccoon he went back in his room (3)

28. Gideon checked out and he left it no doubt (5)

29. To help with good Rocky's revival. (5) to help with good Rocky's survival

Note-The correct wording of each line is given first, and then any errors are presented in italics. In parenthesis is the number of subjects who recalled the line perfectly or the number who made the error if that number is greater than one 
Table 5

Examples of Preservations of End Rhymes

Changed Last Words That Maintained the Same Rhyme Pattern

wonder how you manage to feed the rest wonder how you manage to be caressed

and you know you should be glad and you know you can't be sad

if you say you love me too if you say you love me true

come together right now over me come together right now home to be

and she said listen babe I've got something to say and she said baby that's ok

Changed Last Words That Rhyme with Another Line

lived a man who sailed the sea lived a man old and worm

I wanna be famous, a star of the screen I wanna be famous, as long as it's free

having read the book having read the play

she said you hurt her so she said you hurt her bad

and had you gone you knew in time and if you'd gone you knew it's true

the 1,007 erroneous recalls the last word would change. The 170 errors in the last word we observed are substantially smaller than the 327 expected. The last word of a line holds a very important position.

In 42 of the 170 lines with the last word changed, the substituted word maintained the rhyme pattern. In 55 more of these 170 lines, the new word rhymed with the last word of some other line from the song. Thus, the recalls violated the constraint that last words should rhyme in only 73 cases. For examples of errors that conformed to the end rhyme constraint by maintaining the rhyme pattern or by fitting the line into a different pattern in the song, see Table 5 .

To determine whether this fitting of the substituted words to the rhyme constraints was above chance level, we assessed whether the substituted words rhymed with last words from a different Beatles' song. For each song, the song that was just longer in the selection of songs in this study was used for comparison, except for the longest song, which was compared to the next longest song. When the substituted last words were compared to other songs, only 32 rhymed, whereas 97 rhymed within their own song (this included both the changes that maintained the old rhyme and those that created new rhymes), and a paired $t$ test showed that this difference was significant $[t(24)=6.50, p<.001]$.

Although whether a line rhymed with other lines was not consistently related to how often a line was recalled or to how effectively the line cued the title, it was important in determining the exact words recalled within each line. Figure 1 groups the changes in the last words into those that were changed in lines that rhyme with at least one other line in the song and those that were changed in lines that do not rhyme with any other lines in the song. The substituted last word could have maintained the same rhyme pattern, created a new rhyme pattern by rhyming with a different line or different lines in the song, or made no rhyme. Subjects substituted words that rhymed with the replaced word significantly more often when the line rhymed with at least one other line $\left[x^{2}(2)=6.64, p<.05\right]$.

At the other end of the lines, the subjects also attempted to maintain the poetics. In only 354 of the 1,007 errors was the first word changed. Although this number is about what would be expected if the errors were randomly distributed across word position, the errors often did conform to the poetic constraint. The subjects maintained alliteration by substituting one conjunction or exclamation for another in 59 of these cases. For instance, they would change "but" to "and" or "ooh" to "hey" across their entire recall of a song, preserving an alliteration pattern. In 16 cases, the substituted first word maintained the same alliteration pattern, and in 147 others, it created an al-

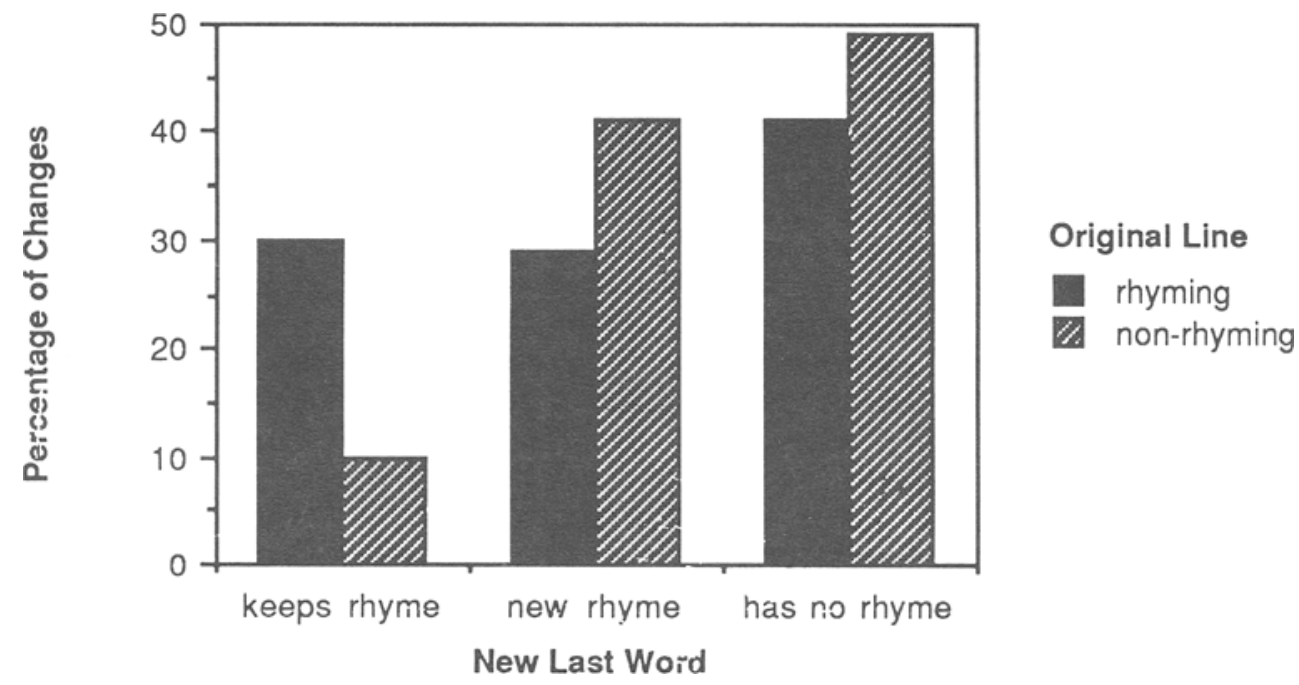

Figure 1. Whether the substituted last word maintained the rhyme pattern as a function of the presence or absence of end rhymes in the original line. 
literation with another line. Thus, in $63 \%$ of these 354 cases in which the first word was changed, the alliteration was maintained in some fashion. Using the same procedure as was used with rhymes, we tested the chance level by checking to see if substituted words would fit the poetic pattern of a comparison song. In $53 \%$ of these cases, the substituted word alliterated with a line in the comparison song. A paired $t$ test found the difference in the predicted direction, but it was not significant $[t(24)=$ $1.67, p=.11]$.

The errors often maintained the poetics within the lines as well. Due to the great number of sounds involved, there is no straightforward way to count the maintenance of poetics or the creation of new poetics or to calculate the chance levels for these phenomena. Nonetheless, the amount of within-line poetics contained in the errors was striking. Some examples of changes that maintained the old sounds or capitalized on sounds to create new poetics are contained in Table 6 .

Errors in encoding or retrieval. To address the concern that the errors may have occurred during perception and not recall, a perception experiment was conducted. The errors made by subjects in transcribing the song "Rocky Raccoon" were compared to those made by the original recall subjects and those made during the perception subjects' own recall of the song 5 days later.

The perception subjects made fewer errors and different kinds of errors than did the original recall subjects. For each line, the percentages of lines and words that were perceived erroneously by the perception sample and recalled erroneously by the original recall sample were computed. The perception subjects made fewer errors than the original recall subjects did, whether one looked at the percentage of lines in error $[9.43 \%$ vs. $18.09 \%$, respec-

Table 6

Examples of Changes that Preserve Within-Line Poetics or Sounds

Changes That Maintained the Same Sounds always know sometimes think it's me

always though sometimes think it's free

he come grooving up slowly

he come moving up slowly

he got toe jam football

he got trojan football

I said something wrong now I long for yesterday

I must move along but I long for yesterday

I sit and meanwhile back

$I$ sit and lean right back

Changes That Created Other Poetics

knows not where he's going to

knows not what he ought to do

I used to get mad at my school

I used to be bad in my school

Holding me down, turning me round

Holding me down, dragging me round

and before too long I fell in love with her

I took one look and I fell in love with her

Note-The sounds of interest are underlined. tively; $t(27)=2.21, p<.05$ ] or the percentage of words in error $[1.41 \%$ vs. $4.71 \%$, respectively; $t(27)=2.63$, $p<.05]$. The errors of the perception sample, given that an error occurred, were smaller than the errors of the memory sample [ 1.37 vs. 1.79 words per error, respectively; $t(93)=2.13, p<.05$ ]. In addition, the perception subjects never changed the last word of a line.

The perception errors did, however, follow the thematic, rhythmic, and poetic constraints, as did the errors by the original recall subjects. Most of the errors by the perception subjects were errors of one word and made complete sense, thus conforming to the thematic constraint. The rhythmic constraint was also followed by the two samples: 38 (73\%) of the 52 lines with errors by the perception sample and $35(80 \%)$ of the 44 lines with errors by the original recall sample maintained the number of syllables. The errors by the perception subjects seemed to conform to the within-line poetics, as did those by the original recall sample, but due to the great amount of sound relations within lines, it is nearly impossible to obtain accurate measures of within-line sound preservations.

Since this perception sample differed from the original recall sample in terms of population (differences in age and university) and in how they learned the song, drawing conclusions from these results is limited. We therefore had the perception subjects recall the song 5 days later and compared the errors made then with their perception errors. When they recalled the song, they made proportionally more errors in the words than they did when recording their immediate perceptions $[27.19 \%$ vs. $1.41 \%$, respectively; $t(27)=9.40, p<.001]$. Many of these changes also conformed to the thematic and poetic constraints. There were few changes that lost the thematic intent of the lines; only $20(15 \%)$ of the 132 lines with errors obviously altered the meaning. Furthermore, 114 (86\%) did not alter the last word of the line, and of the 18 that did, 1 preserved the original sound ending, 6 created new rhymes, and 11 lost the rhyme entirely.

Together, these findings indicate three conclusions. First, errors are made in perceiving the song, but fewer than in recalling it. Second, constraints operate in both perception and memory reconstruction. Third, many of the constrained errors are reconstruction errors.

\section{DISCUSSION}

What have we learned about the way Beatles' songs are remembered? We found that repetition and position in the song were important predictors of the probability that a line would be recalled. We found that whether the line shared words with the title was the most important predictor of the probability that a line would cue the title. Furthermore, we found that recall errors rarely violated the thematic, rhythmic, and poetic constraints of the songs. Thus, different variables appear to be affecting whether a line is recalled, whether it successfully cues the title, and how the recall within each line is constructed.

The different variables that correlated with recall and cuing point out the different processes used in the two 
tasks. In recall, subjects started with the beginning of the song and wrote as much as they could, usually getting at least to the first appearance of the chorus, as is shown by the strong predictive values of primacy and repetition in our data. Similar results can be found in the recall of other verbal materials such as poems, stories, or speeches. Rubin (1977) found that subjects trying to recall the Gettysburg Address started out well and got the first few lines of the speech, but most often at the expense of the important lines that come later in the speech. In cuing the title from a line, whether the line shared words with the title was the strongest predictor, followed by imagery. Subjects looked for information in the one line that tied it to the title and thus enabled them to leap across the other lines. Again, this is much like memory in other material. For example, Paivio (1965) and Rubin (1980) found that imagery has a stronger effect as a cue than as a response in paired-associate learning, and Neisser and Hupcey (1974), who used lines drawn from Sherlock Holmes novels, found that lines with more information (in the form either of images or of important clues to the solution) served more effectively as cues.

Tulving and Watkins (1973; Watkins, 1979) have argued that cued and free recall lie on a continuum. At one end lies the recognition task, where the cue is the item to be recalled. At the other lies the free recall task, where the cue is a request to remember an entire list. In this view, cues vary in specificity. Although this view captures much of what happens, it is incomplete. In cued recall, one item is usually requested, and therefore interitem associations within the list, category, or song play a minimal role. In free recall, many items are requested in whatever order the subjects choose to recall them, and therefore the interitem associations become more important: The recalled items act as subject-provided cues for further recall. Our finding that recall and cuing are best predicted by different variables does not imply that cued and free recall are different processes necessarily. Rather, it appears that not only the specificity of the cue but also the size of the set and the relations among the items to be recalled affects the strategies employed by subjects.

The analyses of which factors were related to the recall of the lines and to cuing from the lines allowed for a description of the processes involved in getting from one unit to others in a set. The error analyses, on the other hand, allowed for a description of the factors that determined memory of the words in each line. Essentially, the error analyses asked the question, "Why are song lyrics recalled so accurately?' 'Part of the answer lies in the demand characteristics of the recall situation. The request for recall of a song, as opposed to a story, probably implies a request for verbatim recall (Rubin, 1977), which explains why subjects attempted to be errorless. The learning conditions explain another part of the answer. The Beatles' songs were learned by our subjects through repeated, spaced exposure over many years, and such a schedule of repetition allows for greater retention (Bahrick, 1979).
The learning and recall conditions, however, cannot explain the phenomena completely. The subjects recalled only about a fifth of the lines. In spite of this, they made few errors in the lines that they did remember. The other factors that complete the explanation of the nearly perfect recall are the constraints of the material. Bartlett (1932) found that subjects' errors were directed by the meaning of the story and kept the general theme while losing some of the specifics. His study, however, had little in the way of constraints other than meaning. Like Bartlett, we looked at the errors made in recalls, and we found that they seldom violated the thematic, rhythmic, or poetic structure of the songs. It is probably the case that much of the verbatim recall observed is due to the limiting effects of multiple constraints. Together, the recall conditions, learning conditions, and structure of the material led to quite accurate recall. We conclude that song recall is based on the same constructive processes as story recall, with the addition of more constraints that make recall more accurate.

At first glance, this could appear counterintuitive; the more a person has to keep track of, the more accurate the person is. In many tasks, as one is required to keep track of more variables, the task grows in difficulty. Therefore, we should expect that keeping track of the rhyme and the rhythm in addition to the meaning should make the task more difficult. But from another perspective, in which the additional variables serve as additional constraints, the conclusion seems obvious (Rubin \& Wallace, 1989). For example, many sets of words can mean "save one's soul." Fewer can be found that do so in three syllables (one is down to "revival," "survival," "salvation," "redemption," "save one's soul," and perhaps a few others). Only two can be found that also provide a weak rhyme with Bible ("revival" and "survival"). Thus, each new variable cuts down the number of words that can fit at any given point, and finding the last word of the last line of "Rocky Raccoon" becomes a much easier task.

Multiple constraints working together in this fashion to efficiently direct word selection for the expression of memories is precisely the type of verbal behavior that would be predicted by a parallel distributed processing model of memory (see, e.g., McClelland, Rumelhart, \& Hinton, 1986) or text comprehension (Kintsch, 1988). One can envision a system of connections between word units based on similarities in meaning and sound (and other properties such as frequency in the language, categorical membership, etc.). As the system learns verbal material, different connections between word units increase in strength. For example, each time a song is heard, connections strengthen between each word unit and the appropriate line units and song units. During recall, all of these constraints (expressed as connections between units) would work together to distinguish words suitable for the memory needing expression. In some cases, the system would have only the meaning and the learned connections to guide recall, but in material where the structure is im- 
portant, more constraints would act in concert to direct recall. The beauty of such a system of constraint-guided recall is that it accounts for correct and erroneous reconstruction with one explanation.

Just as Bartlett (1932) believed that schemas direct both the understanding and the reconstruction of material, so it appears that these constraints affect both the encoding and retrieval of songs. Subjects did make perceptual errors that conformed to the constraints. They made fewer and different errors than did the subjects who were recalling the songs, indicating that many of the constraintguided errors in memory had occurred during reconstruction.

Psychologists often consider memory to be organized around meaning and consider the long-term effects of sound patterns to be minimal. Our results add to the opposition to this view (Alba \& Hasher, 1983; Hasher \& Griffin, 1978; Rubin, 1977). Detailed analysis of the recall protocols provides an indication of the conditions under which surface structure properties can be very important. In the laboratory, surface structure phenomena are usually either not emphasized or else studied where they have little interaction with the meaning (Rubin \& Wallace, 1989). In such cases, they have little effect on memory. In the Beatles' songs, as in most music and poetry, the surface structure constraints are stressed and work with the meaning constraints. Other material in which the surface structure is important and could be predicted to affect recall includes political speeches, jokes and puns, and advertisements. In these situations, multiple constraints should have a marked effect. Isolating variables in order to study them is important, but so is combining the variables to study their interactions. In practice, the number of possible interactions exceeds the resources of the researcher. With more naturalistic material, however, the actual use of multiple constraints can be studied and can provide a more complete picture of how memory works.

\section{REFERENCES}

Alba, J. W., \& HASHeR, L. (1983). Is memory schematic? Psychological Bulletin, 93, 203-231.

BAHRICK, H. (1979). Maintenance of knowledge: Questions about memory we forgot to ask. Journal of Experimental Psychology: General, 108, 296-308.

BARTLETT, F. C. (1932). Remembering: A study in experimental psychology. Cambridge, England: Cambridge University Press.

Fries, C. C. (1952). The structure of English. New York: Harcourt, Brace \& World.

HASHER, L., \& GRIFFIN, M. (1978). Reconstructive and reproductive processes in memory. Journal of Experimental Psychology: Human Learning \& Memory, 4, 318-330.
Horton, D. L., \& MiLls, C. B. (1984). Human learning and memory. Annual Review of Psychology, 35, 361-394.

KaUsLer, D. H. (1974). Psychology of verbal learning and behavior. New York: Academic Press.

Kelly, M. H., \& Rubin, D. C. (1988). Natural rhythmic patterns in English verse: Evidence from child counting-out rhymes. Journal of Memory \& Language, 27, 718-740.

$\mathrm{KINTSCH}, \mathrm{W}$. (1974). The representation of meaning in memory. Hillsdale, NJ: Erlbaum.

KINTSCH, W. (1988). The role of knowledge in discourse comprehension: A construction-integration modal. Psychological Review, 95, 163-182.

Kintsch, W., Kozminsky, E., Streby, W. J., McKoon, G., \& KeENAN, J. M. (1975). Comprehension and recall of text as a function of content variables. Journal of Verbal Learning \& Verbal Behavior, 14, 196-214.

McClelland, J. L., Rumelhart, D. E., \& Hinton, G. E. (1986). The appeal of parallel distributed processing. In D. E. Rumelhart \& J. L. McClelland (Eds.), Parallel distributed processing: Explorations in the microstructure of cognition (pp. 3-44). Cambridge, MA: MIT Press.

Neisser, U. (1982). John Dean's memory: A case study. In U. Neisser (Ed.), Memory observed: Remembering in natural contexts (pp. 139159). San Francisco: W. H. Freeman.

Neisser, U., \& HupCey, J. A. (1974). A Sherlockian experiment. Cog nition, 3, 307-311.

PaIvio, A. (1965). Abstractness, imagery, and meaningfulness in pairedassociate learning. Journal of Verbal Learning \& Verbal Behavior, 4, 32-38.

Paivio, A., Yullle, J. C., \& Madigan, S. (1968). Concreteness, imagery, and meaningfulness values for 925 nouns. Joumal of Experimental Psychology Monographs, 76(1, Pt. 2).

RUBIN, D. C. (1977). Very long-term memory for prose and verse. Journal of Verbal Learning \& Verbal Behavior, 16, 611-621.

RUBIN, D. C. (1978). A unit analysis of prose memory. Journal of Verbal Learning \& Verbal Behavior, 17, 599-620.

RuBIN, D. C. (1980). 51 properties of 125 words: A unit analysis of verbal behavior. Journal of Verbal Learning \& Verbal Behavior, 19, 736-755.

Rubin, D. C., \& Wallace, W. T. (1989). Rhyme and reason: Analyses of dual cues. Journal of Experimental Psychology: Human Memory \& Cognition, 15, 698-709.

SAvile, J. (Ed.). (1979). The Beatles lyrics. London: Macdonal Futura.

Tulving, E., \& Watkins, M. J. (1973). Continuity between recall and recognition. American Journal of Psychology, 86, 739-749.

WALLACE, W. T., \& RUBIN, D. C. (1988a). Memory of a ballad singer. In M. M. Gruenberg, P. E. Morris, \& R. N. Sykes (Eds.), Practical aspects of memory: Current research and issues: Vol. 1. Memory in everyday life (pp. 257-262). New York: Wiley.

Wallace, W. T., \& RUBin, D. C. (1988b). "The wreck of the old 97': A real event remembered in song. In U. Neisser \& E. Winograd (Eds.), Remembering reconsidered: Ecological and traditional approaches to the study of memory (pp. 283-310). Cambridge, England: Cambridge University Press.

WATKINS, M. J. (1979). Engrams as cuegrams and forgetting as cue overload: A cuing approach to the structure of memory. In C. R. Puff (Ed.), Memory organization and structure (pp. 347-372). New York: Academic Press.

(Manuscript received December 14, 1988; revision accepted for publication August 8, 1989.) 